\title{
Case Management for Equitable and Excellent Hospital Services
}

\author{
Prita Muliarini $^{1}$, Fifik Wiryani ${ }^{2}$, M. Nasser ${ }^{3}$, Mokhammad Najih $^{4}$ \\ \{drpritamuliarini@yahoo.com ${ }^{1}$, fwiryani2016@gmail.com ${ }^{2}$, nasserkelly@yahoo.com ${ }^{3}$, \\ mokh.najeh@gmail.com $\left.{ }^{4}\right\}$ \\ ${ }^{1,2,3,4}$ Graduate Programs, Faculty of Law, Universitas Muhammadiyah Malang \\ Kampus III Jl. Raya Tlogomas No. 246 Malang Jawa Timur, Indonesia
}

\begin{abstract}
Patient-centered care as one of the health services quality domains can be implemented effectively and efficiently through the case management service model. The importance of case management is further enhanced by the presence of these factors: increased accountability and transparency in public health services, and the important role in respecting patient rights. However, implementation of case management in the hospital is not yet clearly regulated in existing legal products. The aim of this study was to find the legal basis for case management practice in health facilities within Indonesian laws and regulations. This research used a normative juridical approach. This study found that based on laws and regulations, the hospital organizes plenary individual health services, including preventive, curative, rehabilitative, also promotive in hospital. This service is able to achieve through a coordinated and collaborated continuum of care in the case management process. As mentioned in legislation, respect for patient rights realized through a collaborative partnership approach. This client-centered approach is responsive to the patient's needs, preferences, culture and values. Case management is a health service that upholds health service rights. Namely, participation, accountability, non-discrimination, transparency, upholding human dignity, empowerment and based on legal regulations.
\end{abstract}

Keywords: case management, case managers, service management, patient-centered

\section{Introduction}

One of the basic directions of policies and strategies for national health development 20152019 is to improve public ability to reach excellent and equitable health services [1]. Law Number 36 Year 2009 concerning Health also provides strict regulations regarding: certainty in the implementation of qualified services for the public. Health services must be organized on the basis of humanity, equality, benefits, protection, respect for rights and obligations, justice, nondiscriminating gender and religious norms, as well as guarantees that everyone has the right to obtain safe, excellent and affordable health services [2].

Institute of Healthcare Improvement (IHI) establishes three main health service goals (triple aims) namely improving individual care experience; improving population health; and reducing per capita maintenance costs [3], [4]. Later on it became quadruple aims by adding welfare and work life briefing for health care providers and practitioners [5]. On the other hand, Health care providers are required to provide care to patients effectively, while at the same time reducing health risks and health care costs [6].

Patient-centered service is one of the quality domains of health care [7]. Effective and efficient patient-centered services can be achieved through a case management (CM) service 
model [8]. Meanwhile, safe care transitions require collaboration between service providers throughout the care chain [9]. It is in line with the case management definition, a collaborative process from the assessment, planning, facilities, care coordination, to evaluation and advocacy of options and services in order to fulfill individuals and families comprehensive health needs through communication and available resources, so that patient safety, quality of care, and cost effectiveness can be promoted [10]. CM definition shows that instead of being a single intervention, CM refers to a care package that includes a variety of activities that can vary greatly between programs and are non-duplicative [11].

Case management, also called service management, has two important goals and are often conflicted. Namely, improve the treatment quality for vulnerable populations and control its costs. [12]. While CM's focus is connecting patients to the services needed, this process also involves advocacy and social action as well as ensuring accountability of providers and service systems [12]. Generaly CM is focused on one episode of disease and covers all treatment areas. Especially for the patient or patient population that requires intensive care, like people in the last life stage, often hospitalized, has risky socioeconomic factors and elderly [13]. Thus, Hudon et al., (2019) recommended that $\mathrm{CM}$ is offered to the patients who do not have insurance, have low income or considered in financial need by health care providers and have complex health care needs. The case findings must be combined with high-intensity interventions and/ or involve multidisciplinary/ interorganizational [14].

Effective CM requires the availability of appropriate and coordinated services and can be accessed in a realistic and appropriate time frame [12]. However, CM is not only liaison mechanisms or administrative tools that manage service access, but also a principle that guides provision of various services needed by patients [12]. Moreover, CM is one of the comprehensive care components, not a way to repair inadequate or incomplete maintenance systems [12].

Philosophically CM is based on the fact that when a person reaches optimal levels of health and functional abilities, benefits can be obtained by both individual clients served, the service provider system, the patient reimbursement system, the patient support system, and other parties involved such as entrepreneurs and consumer advocates [10]. Professionally done CM functioned as a tool for achieving client welfare and autonomy through advocacy, ongoing communication, health education, identification of service resources and facilitating services [10]. By implementing CM, client involvement and direct communication between service manager, patients and family or family caregiver and officers will be carried out to optimize health outcomes for all interested parties [10].

It is important to improve accountability and transparency in public health services and appreciate patient rights. The more patient-centered care, care coordination, care or case management and care transition strategies are emphasized, the more desired results are achieved [15]. However, clear legal arrangements for CM implementation in Indonesian hospitals is not yet available. Therefore, this study aims to find its legal and regulatory basis. The study results are expected to encourage excellent CM service model implementation in Indonesian hospitals. So that patient welfare and health services excellence can be achieved optimally.

\section{Research Methods}

This research uses a normative juridical approach that examines library materials and secondary data to compare with regulations and literature related to the problem studied. This study uses primary legal material derived from: Law Number 44 Year 2009 Regarding Hospitals, Law Number 29 Year 2004 Regarding Medical Practice, Minister of Health Regulation No. 4 of 2018 concerning Hospital Obligations and Patients Obligations, Minister of Health Regulation No. 2052 of 2011 concerning Practice License and Medical Practices Implementation and other library materials relevant to the research topic. 


\section{Result and Discussion}

Hospital is a health service institution that conducts individual health services in a complete manner which provides inpatient, outpatient and emergency services to anyone who consults their health problems to obtain the necessary health services, both directly and indirectly [16], [17]. Hospitals must identify populations with modifiable risks by managing and coordinating care to achieve cost savings, quality improvement, and improved patient experience [6].

Case management (CM) model defined as a health service including promotive, preventive, curative, and rehabilitative in hospitals through coordinated and collaborative continuum of care [18] so that patient health is optimally achieved. Continuum of care enables care coordination by creating conditions and relationships that support unlimited interactions between care sectors [19]. Gaps between providers, care teams, settings and information that are important to the plan of care and the flow of patients during treatment will encourage care coordination. Therefore, CM is designed to help patients and work as a support system in managing their medical/ social/ mental health conditions efficiently and effectively [20].

Article 6 paragraph (1) of Minister of Health Regulation Number 4 of 2018 concerning Hospital Obligations and Patients Obligations (latter mentioned as Minister of Health Regulation Number 4/2018) regulated that patients are entitled to get effective and quality service that prioritizes their interest and safety. The service effectiveness will be achieved if the main objectives are met, namely the degree of patient health, individual care experience, population health and care cost per capita [3], [4]. Another equally important objective is the welfare and work life for health care providers and other practitioners [5]. CM has proven effective in decreasing the treatment cost, length of treatment and patient examination numbers [21].

Minister of Health Regulation Number 4/2018 also listed that health services must be implemented in line with hospital service standards as part of good clinical governance (Article 6 paragraph 3) by paying attention to the standard of professional, health worker service and operational procedures as well as professional and hospital ethics code (Article 6 paragraph 4). Institute of Medicine (IOM) specify six quality domains of health services, namely patient safety, effectiveness, efficiency, timely, patient-centered and equality/fair [7]. So that the policies and regulations related to case management in hospitals will support achievement of excellent, effective and patient-oriented hospital services (Article 11).

Change of service orientation from provider-centered care to patient-centered care (PCC) is an appreciation towards patients-rights in health services that are listed in Article 32 of Law 44/2009 and Article 17 of the Minister of Health Regulation 4/2018. Generally, both regulations mentioned that patients are entitled to get excellent, effective and efficient health services. PCC is health service that upholds its rights such as accountability, participation, transparency, nondiscriminative, upholding human dignity, empowerment and legally regulated [22]. PCC notice shift of control and power from the caregiver to the patient, therefore it is a health care quality dimension to the patient's rights [23].

Santana et al., (2018) explain the PCC framework based on the Donabedian's Quality of Care Theory. Quality of PCC is divided into three domains, namely structure, process and outcome. Structure is domain related to the health service system or service context that becomes PCC background. Including required materials, health service resources and organizational characteristics. Process is a domain related to interactions between patients and health care providers. The outcome domain shows the PCC appliance value with other domains relating to interaction results between health care systems, service providers and patients. The framework illustrates practical PCC implementation in sequence, starting from the structural domain as a prerequisite for facilitating the process and influencing PCC outcomes [24].

In health services, patient rights appreciation is realized through a client-centered collaborative partnership approach responsive to the patient's needs, preferences, culture and believed values [10]. It is in line with the CM purpose which empowering patients in overcoming their own problems based on the rights they have, especially related to sensitive information relating to the conditions experienced [12]. 
The patient's rights mentioned in Article 17 the Minister of Health Regulation 4/2018 requires patient's empowerment and involvement during the service. Namely, the right to choose their doctor, treatment class desired, request illness consultation with other doctors, obtain complete information about their condition and submit proposals, suggestions, improvements about the hospital's current treatment. In the case management perspective, patient autonomy and rights become the service focus, as well as optimizing patient's life quality, independence and patient or family function [18].

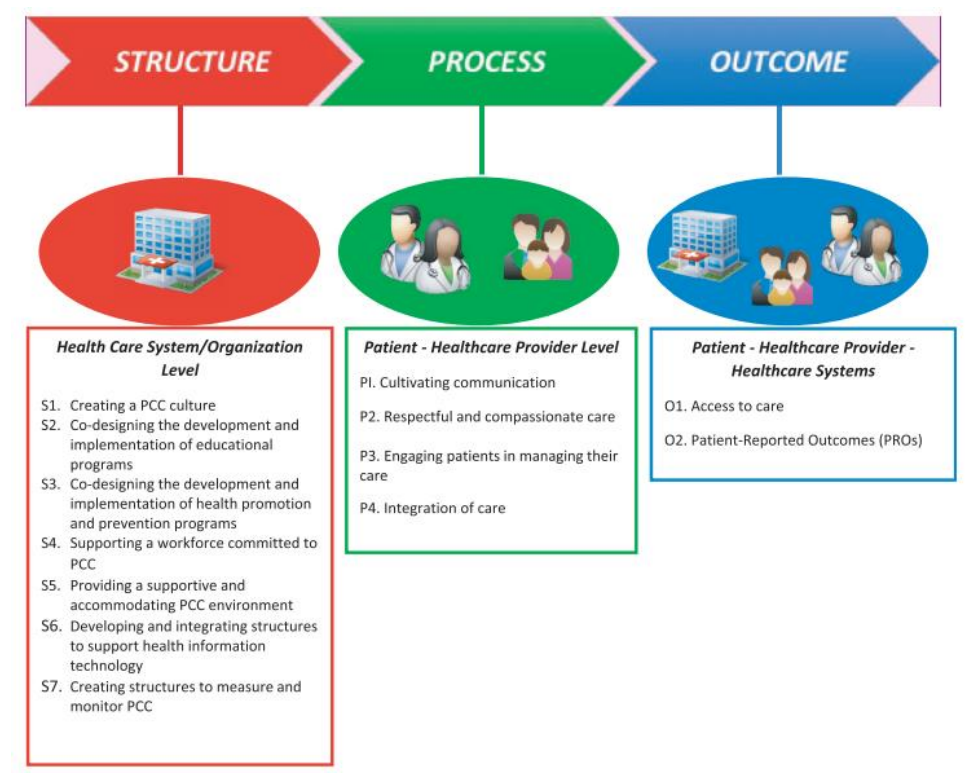

Fig. 1. Implementation framework of Donabedian's quality of patient-centered care (PCC)

[24]

Article 21 the Minister of Health Regulation Number 2052/Menkes/PER/X/2011 Concerning the Practice License and Medical Practice Implementation and Article 39 of the Republic of Indonesia Law Number 29 Year 2004 Concerning Medical Practices listed that medical practice is carried out based on agreement and trust relationship between doctors and patients in order to maintain health, prevent disease, improve health, treat disease and restore health, through maximum healing and restoration effort in accordance with the standard of service, professional and operational procedure as well as patient's medical needs [25], [26].

Case management's principles, interventions and strategies targeting optimal health, function and autonomy of patients, their families and caregivers. This process is achieved through assessment, planning, communication, health education, advocacy, resource management, care coordination and collaboration, and facilitating services. Professional case managers apply these principles in their practice based on the client's needs and value, in order to ensure cooperation between interprofessional health care teams and service provision that is safe, client-centered, appropriate, effective, efficient, timely and fair in terms of care and service [10]. In clinical governance perspective, a case manager with their clinical, managerial and financial skills plays an important role in ensuring quality as a series of efficiency, effectiveness, safety, suitability, participation and equality aspects [13].

In the case management process, the manager has the duties to [18]:

1) Provide case management services to patients and their families.

2) Access and facilitate patient access to programs, services, financial and community resources

3) Provide rehabilitation services, facilitate health, function or optimal productivity and all detailed activities that need to be carried out, especially after serious illness or acute injury. 
4) Manage the utilization of health services, health education, appropriate resources usage, health insurance concept and advocating interests for the benefit of patients and families.

5) Evaluate and measure quality and results. Including assessment, monitoring, data collection results and results evaluation related to patients, as well as emphasize the use of evidencebased practice guidelines in developing case management plans.

6) Comply with ethical, legal and practice standards. Includes compliance with legal, regulatory, ethical, professional and accreditation requirements relating to case management practices and client health education about the right of appeal, and the need for case managers to implement and adhere to standard case management practices.

In Indonesia, the case management service model still faces various challenges. Avia \& Handiyani (2019) in their studies discovered that case manager competency guide is not yet available while laws and regulations require the services provided run by competent personnel [27]. Moreover, case managers involved in their research have not yet received adequate training, unclear performance appraisals, inappropriate job descriptions and have low self-efficacy. Lack of standard competencies and education of case managers will construct risks for hospitals and the health care system [28].

Case managers face several challenges, such as unclear scope of practice, diverse and complex care management activities. Case managers also have a complex relationships with other health care providers and clients due to their role as patient advocate [29]. Role as a case manager is also faced with ethical dilemmas. They have to manage their role as a patient advocate and as the "gatekeeper" of the institution they work for. Therefore, they often have difficulties in balancing both demands. On one side, patients need optimal care and services, on the other side hospitals require strict cost control and resource allocation [18]. As mandated in Article 49 paragraph (1) of Law 29/2004 that every medical service must carry out quality and cost control.

Therefore, development of clear case manager professional guidelines and standards are needed, by combining evidence-based practice and situational learning across health service settings and populations, ongoing case manager competency evaluation and improving system and practices, so that case management service objectives are achieved [30]. It is suggested to involve physical/ medical, behavioral/ cognitive and social determinants during the assessment, intervention and evaluation of case management process [31]. Case managers are required to equip themselves with knowledge related to concepts and strategies of case management, health care costs reimbursement, health care management and provision, concepts of rehabilitation and vocational, psychosocial systems and support [15], quality measurement, results evaluation as well as practice, legal and ethical standards [18]. Besides working along with patients, their families and hospital system, a case manager is also required to work holistically and efficiently, able to manage treatment plans in the most cost-effective manner and possess understanding that quality must not be compromised for financial purposes [32].

\section{Conclusion}

Based on laws and regulations in Indonesia, case management is an equitable and excellent hospital and medical service. Hospitals are obliged to offer this service model to patients who do not have insurance, are low income or considered in need of health services and have complex health care needs. Case management is a service model that encourages optimal health, function and autonomy for patients and their families. If professionally implemented, case management would create services that are safe, client-centered, appropriate, effective, efficient, timely and fair. However, guidelines development and clear case manager professional standards are still needed. As well as incorporating evidence-based practice and situational learning across health service settings and populations and evaluating case manager competencies sustainably. System improvements also need to be made in order to improve practice and achieve service objectives in case management. 


\section{References}

[1] Kementerian Kesehatan RI, Rencana Strategis Kementerian Kesehatan Tahun 2015-2019. Jakarta: Kementerian Kesehatan RI, 2015.

[2] "Undang-Undang Republik Indonesia Nomor 36 Tahun 2009 Tentang Kesehatan," 2009.

[3] IHI, "Triple Aim - Concept Design," Inst. Healthc. Improv., pp. 1-3, 2009.

[4] D. M. Berwick, T. W. Nolan, and J. Whittington, "The triple aim: Care, health, and cost," Health Aff., vol. 27, no. 3, pp. 759-769, 2008.

[5] T. Bodenheimer and C. Sinsky, "From Triple to Quadruple Aim: Care of the Patient," Ann. Fam. Med., vol. 12, no. 6, pp. 573-576, 2014.

[6] AHRQ, "Care Management : Implications for Medical Practice , Health Policy , and Health Services," 2019.

[7] Institute of Medicine, Crossing the Quality Chasm: a New Health System for the 21st Century. National Academy Press, 2001.

[8] D. Lovelace, D. Hancock, S. S. Hughes, P. R. Wyche, C. Jenkins, and C. Logan, "A Patient-Centered Transitional Care Case Management Program," Prof. Case Manag., vol. 21, no. 6, pp. 277-290, 2016.

[9] The Joint Commission, Transitions of Care: The need for a more effective approach to continuing patient care. The Joint Commission, 2013.

[10] CMSA, Standards of Practice for Case Management. Little Rock: Case Management Society of America, 2016.

[11] S. Ross, N. Curry, and N. Goodwin, "Case management: What it is and how it can best be implemented," King's Fund, pp. 1-32, 2011.

[12] A. J. Frankel and S. R. Gelman, Case Management: An Introduction to Concepts and Skills. New York: Oxford University Press, 2016.

[13] E. Fabbri, M. De Maria, and L. Bertolaccini, "Case management: an up-to-date review of literature and a proposal of a county utilization," Ann. Transl. Med., vol. 5, no. 20, pp. 396-396, Oct. 2017.

[14] C. Hudon et al., "Characteristics of Case Management in Primary Care Associated With Positive Outcomes for Frequent Users of Health Care: A Systematic Review," Ann. Fam. Med., vol. 17, no. 5, pp. 448-458, Sep. 2019.

[15] H. M. Tahan, A. C. Watson, and P. V. Sminkey, "What Case Managers Should Know About Their Roles and Functions," Prof. Case Manag., vol. 20, no. 6, pp. 271-296, 2015.

[16] "Undang-Undang Republik Indonesia Nomor 44 Tahun 2009 Tentang Rumah Sakit," 2009.

[17] Permenkes 4 Tahun 2018 tentang Kewajiban Rumah Sakit dan Kewajiban Pasien. 2018.

[18] S. K. Powell and H. M. Tahan, Case Management: A Practical Guide for Education and Practice, 4th ed. Philadelphia: Wolters Kluwer Health, 2019.

[19] WHO, Continuity and coordination of care: a practice brief to support implementation of the WHO Framework on integrated people-centred health services. Geneva: World Health Organization, 2018.

[20] M. McLaughlin-Davis, "The Practice of Hospital Case Management," Prof. Case Manag., vol. 24, no. 6, pp. 280-296, 2019.

[21] C. Grover et al., "Case Management Reduces Length of Stay, Charges, and Testing in Emergency Department Frequent Users," West. J. Emerg. Med., vol. 19, no. 2, pp. 238-244, Mar. 2018.

[22] S. Gloppen, M. Langford, A. Yamin, R. Iunes, L. Cubillio, and M.-L. Escobar, "Operationalizing a Rights-Based Approach to Health Service Delivery," 2015. [Online]. Available: https://www.cmi.no/projects/1791-operationalizing-a-rights-based-approach-to-health. [Accessed: 21Feb-2020].

[23] D. M. Berwick, "What 'Patient-Centered' Should Mean: Confessions Of An Extremist," Health Aff., vol. 28, no. Supplement 1, pp. w555-w565, Jan. 2009.

[24] M. J. Santana, K. Manalili, R. J. Jolley, S. Zelinsky, H. Quan, and M. Lu, "How to practice personcentred care: A conceptual framework," Heal. Expect., vol. 21, no. 2, pp. 429-440, Apr. 2018.

[25] Permenkes Nomor 2052/Menkes/PER/X/2011 Tentang Izin Praktik dan Pelaksanaan Praktik Kedokteran. 2011.

[26] “Undang-Undang Republik Indonesia Nomor 29 Tahun 2004 Tentang Praktik Kedokteran,” 2004.

[27] I. Avia and H. Handiyani, "Analisis Kompetensi Case Manager Pada Rumah Sakit di Jakarta: Studi Kasus," vol. 3, no. 1, pp. 16-27, 2019.

[28] P. Stark, "Advancing Complex Case Management Competencies in a Health Care System," Prof. Case Manag., vol. 25, no. 1, pp. 19-25, 2020.

[29] J. Y. Joo and D. L. Huber, "Case Management Effectiveness on Health Care Utilization Outcomes: A Systematic Review of Reviews," West. J. Nurs. Res., vol. 41, no. 1, pp. 111-133, Jan. 2019.

[30] R. C. Harris and L. L. Popejoy, "Case Management: An Evolving Role," West. J. Nurs. Res., vol. 
41, no. 1, pp. 3-5, Jan. 2019.

[31] CMSA, Case Management Model Act. Case Management Society of America (CMSA), 2017.

[32] M. McLaughlin-Davis, "The Integrated Case Management Program," Prof. Case Manag., vol. 23, no. 3, pp. 147-149, 2018. 